\title{
Iron Oxide Nanoparticles Versus Ferrous Sulfate In Treatment of Iron Deficiency Anemia In Rats
}

\author{
Mona A. El Shemy \\ Department of Clinical Pathology, Faculty of Veterinary Medicine, Benha University, \\ Moshtohor, Toukh 13736, Qalyubia, Egypt
}

$\mathbf{F}$ errous sulfate is the most commonly used drug for treatment of iron deficiency anemia, but it is badly absorbed and causes many unfavorable side effects. Nanotechnology is a way to decrease the side effects of drugs and to increase the drug bioavailability. So, this study is designed to investigate the effect of iron oxide nanoparticles in comparison to ferrous sulphate in the treatment of iron deficiency anemia in rats. Forty male albino rats were divided into two main groups: Control group (10 rats) and anemic group (30 rats) that received standard iron free basal diet for six weeks. Then the anemic group was subdivided into three groups (10 rats) in each group: anemic control group, ferrous sulfate group (received ferrous sulfate $0.4 \mathrm{mg} /$ $\mathrm{kg} \mathrm{b.w/} 10$ days) and iron oxide nanoparticles group (received iron oxide nanoparticles $0.4 \mathrm{mg} /$ $\mathrm{kg} \mathrm{b.w/} 10$ days) in the drinking water. Iron oxide nanoparticlescaused a significant increase in the level of red blood cells $\left(8.80 \pm 0.0510^{6} / \mu \mathrm{L}\right)$, hemoglobin $(18.46 \pm 0.33 \mathrm{~g} / \mathrm{dL})$, hematocrit $(46.66 \pm 0.23 \%)$, mean corpuscular volume (MCV) (53.02 \pm 0.3 FL), mean corpuscular hemoglobin concentration (MCHC) $(39.56 \pm 0.6 \%)$, ferritin $(447.6 \pm 9.02 \mu \mathrm{g} / \mathrm{L})$, transferrin saturation $(138.0 \pm 1.5)$, total iron binding capacity (TIBC) $(145.00 \pm 1.15 \mathrm{mg} / \mathrm{dL})$ and serum iron $(276.33 \pm 2.07 \mathrm{mg} / \mathrm{dL})$. Moreover, it decreased serum malondialdehyde (MDA) (31.85 \pm 0.34 $\mathrm{nmol} / \mathrm{g})$ and C-reactive protein (CRP) $(312.66 \pm 1.7 \mathrm{mg} / \mathrm{L})$ when compared to ferrous sulfate group and anemia control groups. These results revealed that iron oxide nanoparticles proved as an effective drug for the treatment of iron deficiency anemia in rats.

Keywords: Anemia, Blood picture, Iron nanoparticle, Oxidative stress, Inflammatory indicators, Rats

\section{Introduction}

One of the most common nutritional deficiencies in the world is the iron deficiency anemia in which there is a reduction in the capacity of red blood cells to deliver oxygen to the body cells and tissues [1]. Since iron is a main component of hemoglobin, myoglobin and some enzymes, the deficiency of iron causes weakness, fatigue, pale skin, difficult learning and headaches A lot of people don't know that they suffer from iron deficiency anemia. Inadequate iron intake and decreased iron absorption are the most important causes of iron deficiency anemia that can be diagnosed by low iron stores and hemoglobin than normal [2].

Ferrous sulfate is a commonly used drug for the treatment of iron deficiency anemia, but the ferrous sulfate application may be limited as it causes constipation, nausea, abdominal discomfort, dark colored stool and unfavorable changes in colon bacteria [3]. When the iron compounds are taken by mouth with low bioavailability it needs high dose of iron to absorb the needed amount, but the remained unabsorbed amount can cause several undesirable gastrointestinal complications. The remained unabsorbed iron can react with hydrogen peroxide and superoxide producing free radicals. So, it is difficult for patient to take the medicine regularly due to these complications [4].

Recently, nanotechnology causes dramatic increase in the bioavailability of nutrients. When iron oxide nanoparticles were used as a source for oral intake of iron, iron absorption increased 1.35 times compared to ferrous sulfate [5]. Therefore, it is expected that using of iron oxide nanoparticle, its bioavailability increases, and lower doses of drug needed consequently decrease its side effects in gastrointestinal system that helps the patient to continue the medication. 
Therefore, this experiment is designed to study the possible impact of iron oxide nanoparticles supplementation as a therapy for in vivo iron deficiency anemia in rats when compared to treatment of anemia by ferrous sulfate.

\section{Material and Methods}

\section{Chemicals}

Iron oxide nanoparticles (Iron oxide nanoparticles, Sigma Chemical Co., St. Louis, MO, USA) were administered in drinking water at a dose of $0.4 \mathrm{mg} /$ day for ten days according to Shafie et al. [4]. Ferrous sulfate seven hydrate (Ferrous sulfate, Sigma Chemical Co., St. Louis, MO, USA) was administrated at a dose of $0.4 \mathrm{mg} /$ day for ten days according to Shafie et al. [4].

\section{Experimental animals}

In this study, forty male albino rats with average body weight $125 \mathrm{gm}$ were used. Rats were obtained from the Experimental unit, Faculty of Veterinary Medicine, Benha University, Egypt. Rats were kept in separate clean metal cages. Clean and fresh drinking water was supplied ad libtium. Acclimatization of rats was achieved by leaving rats for 15 days before starting of the experiment. Rats were kept at constant environmental and nutritional condition throughout the period of the experiment.

\section{Preparation of iron-free basal diet}

Standard iron free basal diet was prepared from fine ingredients. It is composed of $10 \%$ sunflower oil, $4 \%$ salt mixture, $1 \%$ vitamin mixture, $2 \%$ choline chloride, $12 \%$ DL- methionine and cornstarch up to $100 \mathrm{~g}$ [7].

\section{Sampling}

Blood was collected by scarification at the end of the experiment. Blood was collected into two tubes: the first plain centrifuge tube to separate serum for biochemical analysis (MDA, Serum Iron, TIBC, CRP, ferritin and transferrin saturation) and the second one on EDTA tube for hematological examination.

\section{Determination of blood parameters}

Complete blood count $(\mathrm{CBC})$ was calculated by using automatic cell counter. The red blood cell indices were done through equations.

\section{Determination of C Reactive Protein (CRP)}

CRP was measured by ELISA method. The standards, control and samples of serum are incubated in coated wells with polyclonal antirat CRP antibody. After wash, polyclonal anti- rat CRP antibody labelled with horseradish peroxidase and incubated, the free components are washed. TMB solution is then added to each well. The wells that contain CRP and HRP conjugated CRP antibody will appear blue in color. These wells turn to yellow color after addition of stop solution. The optical density (OD) is measured spectrophotometrically at wave length of $450 \mathrm{~nm}$. The concentration of CRP is proportional to the value of $\mathrm{OD}$ value. The concentration of CRP in the samples is measured through the standard curve.

\section{Determination of serum ferritin}

Serum ferritin was measured by quantitative sandwich ELISA method by using rat ferritin. A monoclonal ferritin antibody pre-coated onto the microplate. Samples and Standards are pipetted into the wells and any ferritin present is bounded by the immobilized antibody. An enzyme-linked monoclonal antibody specific for Ferritin is added to the wells. Wash to remove any unbound antibody-enzyme reagent, a substrate solution is added, and the color develops in proportion to the concentration of ferritin in the samples

\section{Determination of transferrin saturation}

Rat transferrin ELISA kits by colorimetric competitive in serum. A transferrin specific antibody has been precoated onto 96 -well plates and blocked. Samples and standards are added to the wells and then transferrin then washing with buffer. Strptavidin-Peroxidase Conjugate is added, and unbound conjugates are washed away with buffer. TMB is then added. TMB is catalyzed by Strptavidin-Peroxidase to produce a blue color that changes to yellow after adding stop solution. The density of yellow color is inversely proportional to the amount of transferrin captured in plate.

\section{Determination of lipid peroxidation by-products}

Lipid peroxidation by-products malondialdehyde (MDA) in liver tissue homogenate was performed according to Ohkawa et al., [6] based on the reaction of the thiobarbituric acid with malondialdehyde in acidic media at $95^{\circ} \mathrm{C}$ for $45 \mathrm{~min}$ to form thiobarbituric acid-reactive substances (TBARS). The resulting pink-colored reaction product was extracted with n-butanol and the absorbance was determined at $535 \mathrm{~nm}$ using a spectrophotometer (Model, JASCO 7800, UV/VIS, Japan). The level of lipid peroxide was expressed as nmol $/ \mathrm{g}$ protein.

\section{Experimental design}

Forty male albino rats were divided into 
two main groups: control group (10 rats) that received normal diet till the end of experiment, and anemic group (30 rats) that received standard iron free basal diet for six weeks to induce iron deficiency anemia. Then after induction of anemia, the anemic group was subdivided into three subgroups (10 rats) in each sub group that were fed normal diet for 10 days: anemic control group, ferrous sulfate group and iron oxide nanoparticles group were administered in the drinking water at concentration of $0.4 \mathrm{mg} / \mathrm{kg}$ body weight for ten days. This study was performed in accordance to the Institutional Animal Care and Use (IACAU) of Benha University. Blood were collected by scarification at the end of experiment. Blood was collected into two tubes: the first plain centrifuge tube to separate serum for biochemical analysis (MDA, Serum Iron, TIBC, CRP, ferritin and transferrin saturation) and the second one on EDTA tube for hematological examination.

\section{Statistical Analysis}

Statistical analysis was performed using the statistical software package SPSS for Windows (Version 16.0, SPSS Inc., Chicago, Ill). The significance of differences between more than two groups was evaluated by one-way analysis of variance (ANOVA). If one-way ANOVA indicated a significant difference, then differences between individual groups were estimated using Fisher's least significant difference (LSD) test. Results are expressed as the mean \pm standard error of the mean (SEM). A $P$-value of less than 0.05 was considered significant [8].

\section{$\underline{\text { Results }}$}

Hematological Results

Table 1 showed the effect of iron-free basal diet after 6 weeks of administration. There was significant decrease in RBCs count, hemoglobin concentration, hematocrit value with significant decrease in MCV and MCHC in anemia group when compared to control group.

In Table 2, there was a significant decrease in RBCs count, hemoglobin concentration and hematocrit value with significant decrease in $\mathrm{MCV}$ and $\mathrm{MCHC}$ in anemia group resulting in a case of microcytic hypochromic anemia when compared to control group. There was a significant decrease in RBCs count, hemoglobin concentration, hematocrit value in ferrous sulfate group in comparison with control group. Meanwhile, there was no significant change in RBCs count, hemoglobin concentration, hematocrit value, $\mathrm{MCV}$ and $\mathrm{MCHC}$ in iron oxide nanoparticle group when compared to control group. On the other hand, there was significant increase in RBCs count, hemoglobin concentration, hematocrit value in iron oxide nanoparticles group when compared to ferrous sulfate group.

Serum ferritin, transferrin saturation, total iron binding capacity and serum iron levels:

Table 3 showed a significant decrease in serum ferritin, transferrin saturation, and serum iron with a significant increase in total iron binding capacity levels in anemia group when compared to control group. Moreover, there was significant increase of serum ferritin, transferrin saturation and serum iron levels in iron oxide nanoparticles and ferrous sulfate groups when compared to control group and anemia group. Moreover, there was no significant change in total iron binding capacity level in iron oxide nanoparticles group when compared to control group. Meanwhile there was significant increase in total iron binding capacity in ferrous sulfate group when compared to control group and iron oxide nanoparticles group.

TABLE 1. Effect of iron-free basal diet on red blood cells count (RBCs), hemoglobin (Hb) concentration, hematocrit (Hct \%), mean corpuscular volume (MCV) andmean corpuscular hemoglobin concentration (MCHC) after 6 weeks in Control and Anemia groups (Mean \pm S.E.M) $(n=3-4)$.

\begin{tabular}{lll}
\hline Parameter & Control & Anemia \\
\hline RBCs $\left(10^{6} / \mu \mathrm{L}\right)$ & $9.00 \pm 0.15^{\mathrm{a}}$ & $6.92 \pm 0.06^{\mathbf{b}}$ \\
$\mathrm{Hb}(\mathrm{g} / \mathrm{dL})$ & $18.55 \pm 0.21^{\mathrm{a}}$ & $12.40 \pm 0.20^{\mathbf{b}}$ \\
$\mathrm{Hct}(\%)$ & $47.17 \pm 0.17^{\mathrm{a}}$ & $32.70 \pm 0.72^{\mathrm{b}}$ \\
$\mathrm{MCV}(\mathrm{FL})$ & $52.41 \pm 0.94^{\mathrm{a}}$ & $47.25 \pm 0.98^{\mathbf{b}}$ \\
$\mathrm{MCHC}(\%)$ & $39.65 \pm 0.47^{\mathrm{a}}$ & $37.94 \pm 0.88^{\mathrm{b}}$ \\
\hline
\end{tabular}

Means with different superscripts within the same row were significantly different 
TABLE 2. RBCs count, Hb concentration, Hct \%, MCV and MCHC in Control, Anemia, Ferrous sulfate and Iron oxide nanoparticles groups (Mean \pm S.E.M) $(n=3-4)$.

\begin{tabular}{lcccc}
\hline \multicolumn{1}{c}{ Parameter } & Control & Anemia & Ferrous sulfate & $\begin{array}{c}\text { Iron oxide } \\
\text { nanoparticles }\end{array}$ \\
\hline $\mathrm{RBCs}\left(10^{6} / \mu \mathrm{L}\right)$ & $08.83 \pm 0.08^{\mathrm{c}}$ & $06.83 \pm 0.06^{\mathrm{a}}$ & $07.53 \pm 0.03^{\mathrm{b}}$ & $08.80 \pm 0.05^{\mathrm{c}}$ \\
\hline $\mathrm{Hb}(\mathrm{g} / \mathrm{dL})$ & $18.46 \pm 0.33^{\mathrm{c}}$ & $12.13 \pm 0.14^{\mathrm{a}}$ & $16.56 \pm 0.18^{\mathrm{b}}$ & $18.46 \pm 0.33^{\mathrm{c}}$ \\
\hline $\mathrm{Hct}(\%)$ & $46.73 \pm 0.41^{\mathrm{c}}$ & $32.16 \pm 0.61^{\mathrm{a}}$ & $42.27 \pm 1.70^{\mathrm{b}}$ & $46.66 \pm 0.23^{\mathrm{c}}$ \\
\hline $\mathrm{MCV}(\mathrm{FL})$ & $52.91 \pm 0.9^{\mathrm{b}}$ & $47.07 \pm 0.70^{\mathrm{a}}$ & $52.78 \pm 1.30^{\mathrm{b}}$ & $53.02 \pm 0.03^{\mathrm{b}}$ \\
\hline $\mathrm{MCHC}(\%)$ & $39.51 \pm 0.57^{\mathrm{b}}$ & $37.74 \pm 0.90^{\mathrm{a}}$ & $39.30 \pm 1.40^{\mathrm{b}}$ & $39.56 \pm 0.60^{\mathrm{b}}$
\end{tabular}

Means with different superscripts within the same row were significantly different.

TABLE 3. Ferritin, Transferrin saturation, TIBC, Serum iron, C-reactive protein and MDA in Control, Anemia, Ferrous sulfate and Iron oxide nanoparticles groups (Mean \pm S.E.M) $(n=34-)$.

\begin{tabular}{lcccc}
\hline \multicolumn{1}{c}{ Parameter } & Control & Anemia & Ferrous sulfate & $\begin{array}{c}\text { Iron oxide } \\
\text { nanoparticles }\end{array}$ \\
\hline Ferritin $(\mu \mathrm{g} / \mathrm{L})$ & $468.3 \pm 1.70^{\mathrm{d}}$ & $331.6 \pm 5.80^{\mathrm{a}}$ & $366.0 \pm 3.10^{\mathrm{b}}$ & $447.6 \pm 9.02^{\mathrm{c}}$ \\
Transferin saturation & $118.3 \pm 2.10^{\mathrm{b}}$ & $98.00 \pm 1.70^{\mathrm{a}}$ & $128.0 \pm 1.10^{\mathrm{c}}$ & $138.0 \pm 1.50^{\mathrm{d}}$ \\
TIBC $(\mathrm{mg} / \mathrm{dL})$ & $145.3 \pm 2.02^{\mathrm{b}}$ & $119.3 \pm 1.40^{\mathrm{a}}$ & $150.0 \pm 0.57^{\mathrm{c}}$ & $162.3 \pm 1.20^{\mathrm{d}}$ \\
Serum iron $(\mathrm{mg} / \mathrm{dL})$ & $243.6 \pm 1.40^{\mathrm{c}}$ & $183.3 \pm 3.17^{\mathrm{a}}$ & $213.0 \pm 1.70^{\mathrm{b}}$ & $276.3 \pm 2.07^{\mathrm{d}}$ \\
CRP $(\mathrm{mg} / \mathrm{L})$ & $331.0 \pm 1.40^{\mathrm{b}}$ & $372.6 \pm 1.40^{\mathrm{d}}$ & $341.0 \pm 1.50^{\mathrm{c}}$ & $312.6 \pm 1.70^{\mathrm{a}}$ \\
MDA $(\mathrm{nmol} / \mathrm{g})$ & $31.72 \pm 0.90^{\mathrm{a}}$ & $48.00 \pm 0.70^{\mathrm{c}}$ & $36.31 \pm 1.20^{\mathrm{b}}$ & $31.85 \pm 0.34^{\mathrm{a}}$ \\
\hline
\end{tabular}

Means with different superscripts with in the same row were significantly different.

Serum malondialdehyde (MDA) and C-reactive protein $(C R P)$

Table 2 showed a significant increase in serum malondialdehyde and CRP levels in anemia group and ferrous sulfate group when compared to control group. Moreover, there were no significant changes of serum MDA and CRP in iron oxide nanoparticles group when compared to control group. On the other hand, a significant reduction of serum MDA and CRP levels were found in iron oxide nanoparticles group when compared with ferrous sulfate group and anemia group.

\section{Discussion}

Iron oxide nanoparticles are commonly used nanoparticles in medicine and biotechnology [9]. Iron oxide nanoparticles are the most investigated nanoparticles due to their excellent biocompatibility and bioavailability and their ease of synthesis for biomedical applications and treatment of various diseases $[10,11,12]$. These

Egypt. J. Vet. Sci. Vol. 49, No.2 (2018) nanoparticles are promising substances for the efficient absorption of drugs [13, 14].

In this study, iron oxide nanoparticles administration induced a significant increase in RBCs count, hemoglobin concentration, and packed cell volume when compared to ferrous sulfate group in treatment of anemia. It may be due to its marked small size that increased the bioavailability and absorption of iron oxide nanoparticles [15]. These effects of iron oxide nanoparticles on RBCs, hemoglobin concentration and hematocrit matched with Shafie et al. [4]. Furthermore, the blood indices revealed the presence of microcytic hypochromic anemia in the group that fed iron-free basal diet. By treatment with iron oxide nanoparticles or ferrous sulfate, there was no significant change in the blood indices than control. Our result matched with Hashem et al. [7] who reported a significant increase in red blood cell indices in iron oxide nanoparticles group when compared to anemic 
group which may be due to the effectiveness of iron oxide nanoparticles in treatment of anemia.

Our study showed that administration of iron oxide nanoparticles in rats in a dose of $0.4 \mathrm{mg}$ per day for 10 days after induction of anemia is very effective in treatment of the anemic state than ferrous sulfate. This is evidenced by significant increase in serum iron, ferritin and transferrin saturation than anemia group and ferrous sulfate group. The elevation of the level of serum iron, ferritin and transferrin saturation is an indicator of relieving the anemic state [16]. In anemic group, there was significant increase in total iron binding capacity which may be due to that the increased production of transferrin by the liver in attempt to maximize the use of little iron that is available. Meanwhile, in iron oxide nanoparticles group, there was no significant change in total iron binding capacity when compared to control group. On comparing iron oxide nanoparticles group with ferrous sulfate group, there was significant decrease in total iron binding capacity that ascertain the effectiveness of iron oxide nanoparticles than ferrous sulfate in treating anemia. Our result matched with Shafie et al. and Zariwala et al. [4,17]. In addition, there was a significant decrease in serum MDA level in iron oxide nanoparticle group when compared to ferrous sulfate group which confirms the effectiveness of iron oxide nanoparticles to remove the oxidative stress which may be due to the production of free radicals by ferrous sulfate through Fenton reaction that is made by the remaining free iron unabsorbed from ferrous sulfate [18]. Our results matched with other studies $[19,4,20]$, who reported that iron oxide nanoparticles decrease MDA levels than ferrous sulfate.

$\mathrm{C}$-reactive protein is a widely used routine marker of acute inflammation. In anemic group, there was significant increase in C-reactive protein when compared to control group. The elevated serum CRP resulted in impaired iron absorption with interaction with iron metabolism and reduction of serum transferrin [21,22]. Meanwhile, there was significant decrease in C-reactive protein in iron oxide nanoparticles group when compared to anemia group and ferrous sulfate group. Our results agreed with other studies $[4,23]$, they ascertained that iron oxide nanoparticles administration decreases C-reactive proteins.
In conclusion, iron oxide nanoparticle are potent anti-inflammatory substances than ferrous sulfate in treatment of iron deficiency anemia and it should be used when it is only indicated and under medical supervision and follow up.

Acknowledgements: To all stuff member of clinical pathology department, Benha univeristy

Funding statements: No funding sponsor

Conflicts of interest: No conflict of interest

\section{References}

1. Theil, E.C. Iron, ferritin and nutrition. Annu Rev of Nutr, 24, 327-43 (2004).

2. Low, M. Farrell, A. Biggs, B.A and Pasricha, S.R Effects of daily iron supplementation in primaryschool-aged children: Systematic review and meta-analysis of randomized controlled trials: CMAJ, 185, 791-802 (2013).

3. Werner, T. Wagner, S.J Martinez, I. Walter, J. Chang JS, Clavel T. Depletion of luminal iron alters the gut microbiota and prevents Crohn's disease-like ileitis.: Gut, 60, 325-333 (2011).

4. Shafie, E.H Keshavarz, S.A, Kefayati, M.E Taheri, F. Sarbakhsh, P. and Vafa, M.R The effects of nanoparticles containing iron on blood and inflammatory markers in comparison to ferrous sulphate in anemic rats. Int. J. Prev. Med., 32, 7-17 (2016).

5. Gao, H. Chen, H. Chen, W. Tao, F. Zheng, Y. and Jiang, Y. Effect of nanometer pearl powder on calcium absorption and utilization in rats. Food Chem, , 109, 493-498 (2008).

6. Ohkawa, H. Hiroshi, A. Nobuko, O. Assay for lipid peroxides in animal tissues by thiobarbituric acid reaction. Analytical Biochemistry, 95, 351358 (1979).

7. Hashem, F. Nasr, M. and Ahmed, Y. Preparation and evaluation of iron oxide nanoparticles for treatment of iron defficiency anemia. International Journal of Pharmacy and Pharmaceutical Science, 10, 142-146 (2018).

8. Schmittgen, Thomas, D. and Kenneth, J. Analyzing real-time PCR data by the comparative CT method. Nature Protocols, 3, 1101-1108 (2008). 
9. Ramchand, C.N Priyadarshini. P. Kopcansky, P. and Mehta, R.V Applications of magnetic fluids in medicine and biotechnology . Indian J. Pure. Appl. Phys., 39, 683-689 (2001).

10. Sun, C. Lee, J. and Zhang, M. Magnetic nanoparticles in NMR imaging and drug delivery . Adv. Drug Deliv. Rev., 60, 1252-1265(2008).

11. Thorek, D.L, Chen, A.K Czypryna, J. and Tsourkas, A. Superparamagnetic iron oxide nanoparticle probes for molecular imaging. Ann. Biomed. Eng., 34, 23-38 (2006).

12. Bhaskar, S. Tian, F. Stoeger, T. Kreyling, W. Fuenteet, J. M de la, Grazu, V. Borm, P. Estrada, G. Ntziachristos, V. and Razansky, D. Multifunctional nanocarriers for diagnostics, drug delivery and targeted treatment across blood brain barrier Perspectives on tracking and neuroimaging. Part Fibre. Toxicol., 7, 1-3 (2010).

13. Pandey, P. and Dahiya, M.A. Brief review of inorganic nanoparticles. J. Crit. Rev., 3, 18-26 (2016).

14. Patil, P. and Bhoskar, M. Optimization and evaluation of spray dried chitosan nanoparticles contaning doxorubicin. Int. J. Curr. Pharm. Res., 6, 7-15(2014).

15. Hilty, F.M. Arnold, M. Hilbe, M. Telek, A Knijnenburg, J.T. and Ehrensperger, F. Iron from nanocompounds containing iron and zinc is highly bioavaiable in rats without tissue accumulation, Nat. Nanotechnol, 5, 374-380 (2010).

16. Criswell, K.A Sulkanen, A.P Hochbaum, A.F and Bleavins, M.R Effects of phenylhydrazine or phlebotomy on peripheral blood, bone marrow and erythropoietin in Wistar rats. J. Appl. Toxicol., 20, 25-34 (2000).

17. Zariwala, M.G Elsaid, N. Jackson, T.LCorral, L.F Farnaud, S. Somavarapu, S. A novel approach to oral iron delivery using ferrous sulphate loaded solid lipid nanoparticles. Int. J. Pharm., 456, 400407(2013).

18. Carrier, J. Aghdassi, E. Cullen, J. and Allard, J.P Iron supplementation increases disease activity and vitamin $\mathrm{E}$ ameliorates the effect in rats with dextran sulfate sodium- induced colitis. J. Nutr., 132, 3146- 3150(2002).

Egypt. J. Vet. Sci. Vol. 49, No.2 (2018)
19. Powell, J.J Bruggraber, S.F, Faria, N. Poots, L.K Tagmount, M.A Aslam, M.F . Nanoparticulate iron (III) oxo-hydroxide delivers safe iron that is well absorbed and utilised in humans. Nanomedicine, 10, 1877-1886 (2014)

20. Akarsu, S. Demir, H. Selek, S. and Oguzonul, F. Iron deficiency anemia and levels of oxidative stress induced by treatment modality Pediatrics. International, 55, 239- 295(2013).

21. Jurado, R.L Iron, infections, and anemia of inflammation. Clin. infect. Dis., 25, 888895(1997).

22. Vermeire, S. Van, A.G Rutgeerts, P. Laboratory markers in IBD: useful, magic, or unnecessary, Gut, 55 (3) 426-431 (2006). doi: 10.1136/ gut.2005.069476

23. Breiterman, W.R C- reactive protein and anemia: implications for patients on dialysis. Nephrol. Nurs. J., 34, 134-142 (2006).

(Received 16/05/2018; accepted 08/08/2018) 


\title{
تأثير جزيئات نانو اكسيد الحديد مقابل سلفات الحديد فى علاج انيميا نقص الحديد في \\ منى عبد الظاهر الثشيمي \\ قسم الباثولو جيا الإكلينيكية ، كلية الطب البيطري ، جامعة بنها ، مصر.
}

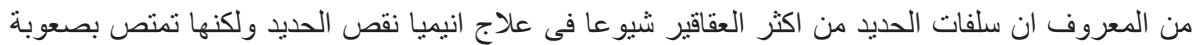

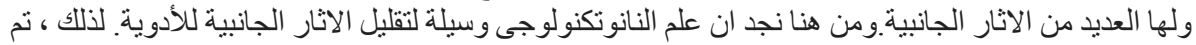

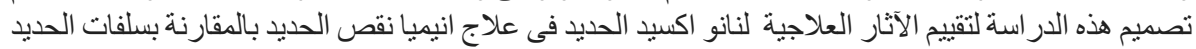

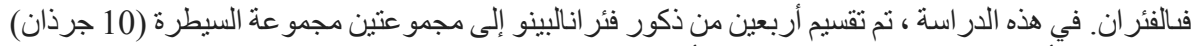

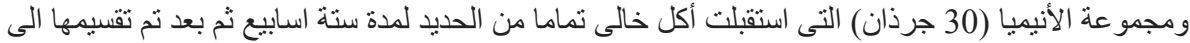

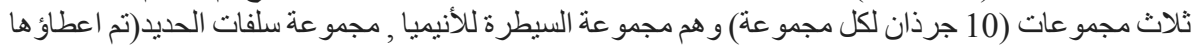

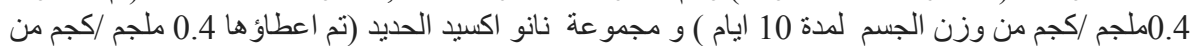

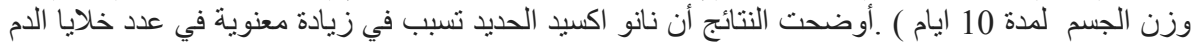

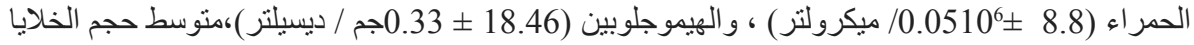

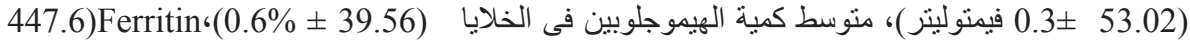

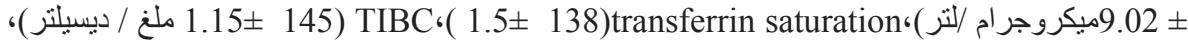
ونانومول/31.85)MDA ومجموعة الأنيميا. وقد خلص إلى أن نانو اكسيد الحديد عقار فعال فى علاج انيميا نقص الحديد فى الفئران. الكلمات الداله: انيميا ، جزيئات نانو الحديد ، الاجهاد التأكسدى ومؤشرات الالتهاب.
\end{abstract}

